\title{
Randomized controlled trial study of the effects of an online divorce platform on anxiety, depression, and somatization.
}

Hald, Gert Martin; Ciprić, Ana; Øverup, Camilla Stine; Štulhofer, Aleksandar; Lange, Theis; Sander, Søren; Gad Kjeld, Simone; Strizzi, Jenna Marie

Source / Izvornik: Journal of Family Psychology, 2020, -

Journal article, Accepted version

Rad u časopisu, Završna verzija rukopisa prihvaćena za objavljivanje (postprint)

https://doi.org/10.1037/fam0000635

Permanent link / Trajna poveznica: https://urn.nsk.hr/urn:nbn:hr:131:231414

Rights / Prava: In copyright/Zaštićeno autorskim pravom.

Download date / Datum preuzimanja: 2023-04-26

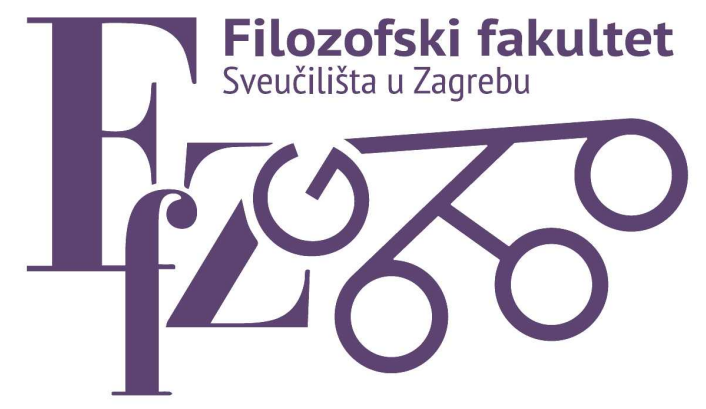

Repository / Repozitorij:

ODRAZ - open repository of the University of Zagreb

Faculty of Humanities and Social Sciences
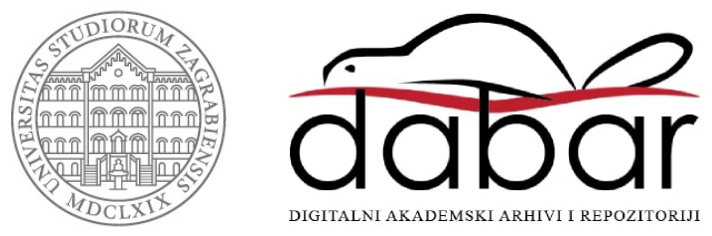
RCT Study of the Effects of an Online Divorce Platform on Anxiety, Depression, and Somatization

\author{
Gert Martin Hald ${ }^{\mathrm{a}}$ \\ Ana Ciprića \\ Camilla Stine Øverup ${ }^{\mathrm{a}}$ \\ Aleksandar Štulhofer ${ }^{\mathrm{b}}$ \\ Theis Lange ${ }^{\mathrm{a}}$ \\ Søren Sander ${ }^{\mathrm{a}}$ \\ Simone Gad Kjeld ${ }^{\mathrm{a}}$ \\ Jenna Marie Strizzi ${ }^{a}$
}

${ }^{a}$ Department of Public Health, Faculty of Health and Medical Sciences, University of Copenhagen, Denmark ${ }^{\mathrm{b}}$ Department of Sociology, Faculty of Humanities and Social Sciences, University of Zagreb, Croatia

Running Head: DIGITAL DIVORCE INTERVENTION AND MENTAL HEALTH

Address for Correspondence:

Address: Øster Farimagsgade 5B, 1014 København K, Copenhagen, Denmark

Phone: +4528731317

E-mail: ghald@sund.dk 


\section{Manuscript submission}

The manuscript has not been submitted elsewhere.

\section{Acknowledgments}

We wish to thank the Egmont Foundation for support with the development of the digital platform 'Cooperation After Divorce', the Danish State Administration for help during the data collection process, and the Carlsberg Foundation for their funding of the research project 'When Marriage Fails'.

\section{Funding}

This work was supported by financial support from 'The Carlsberg Foundation Distinguished Associate Professor Fellowship' (the first author) under Grant No. CF16-0094.

\section{Compliance with Ethical Standards}

All procedures performed in studies involving human participants were in accordance with the ethical standards of the institutional and national research committee and with the 1964 Helsinki declaration and its later amendments or comparable ethical standards. Informed consent was obtained, and participants were informed about the study, its content, and volunarity of participation. Responses were anonymized and stored in anonymous form on a secure server. The Study was approved by the Danish Data Protection Agency. The study was exempt from further ethical evaluations following the rules and regulations as set forth by the Scientific Ethical Committees of Denmark.

\section{Conflict of Interest \& Author Disclosure Statement}

For due diligence, we would like to declare that the University of Copenhagen, Denmark, where the authors work, owns the digital intervention platform 'Cooperation after Divorce (CAD)' while two of the co-authors (Gert Martin Hald and Søren Sander) holds the 
commercial license and intellectual property rights to the platform through the Company 'Cooperation after Divorce' (Samarbejde Efter Skilsmisse ApS).

Data Accessibility Statement

Due to data sensitivity, data cannot be shared publicly. Data analysis syntax is available upon request. 


\begin{abstract}
Divorce is associated with a range of negative psychological consequences including increased symptoms of anxiety, depression, and somatization. The current study presents the results of a one-year longitudinal randomized controlled trial study of the Cooperation after Divorce online intervention platform for adults going through a divorce. Participants included 1,856 Danish divorcees who, on average, began the intervention within one week of legal divorce and responded to the SCL-90R anxiety, depression, and somatization subscales at baseline, 3, 6, and 12 months post juridical divorce. Data analyses consisted of linear mixed effect model analyses, mean group comparisons, and one-sample t-tests to compare the 12-month follow-up with national normative data. The study found that the intervention platform significantly reduced anxious, depressive and somatization symptoms among divorcees in the intervention group over a one-year period and that the magnitude of these effects was large in effect size (Cohen's $(d)=$ >.78). Further, it was found that at one year post divorce, symptom levels of all three outcomes were close to the population norms for participants in the intervention group but still considerable elevated for participants in the control group. The findings suggest that online intervention platforms may be effective in reducing adverse mental health related effects of divorce and thereby offer long-term human and public health benefits.
\end{abstract}

Keywords: Depression; Anxiety; Somatization; Divorce; Marital Dissolution; RCT; Online Intervention 


\section{Introduction}

Many families experience marital (or relationship) dissolution and divorce rates in industrialized countries are generally high ranging from 35-50\% (Center for Disease Control and Prevention, 2016; European Commission, 2015). In the US alone, approximately 2.5 million adults are divorcing every year (Malgaroli, Galatzer-Levy, \& Bonanno, 2017). Due to the disruptive nature of divorce, divorce has increasingly been considered a public health concern (Bracke, Colman, Symoens, \& Van Praag, 2010; Monden, Metsä-Simola, Saarioja, \& Martikainen, 2015; Salem, Sandler, \& Wolchik, 2013; Vezzetti, 2016) and divorce is classified as one of the most stressful life events during adulthood (Lorenz, Wickrama, Conger, \& Elder, 2006; Mather, Blom, \& Svedberg, 2014).

Divorce has been found to be associated with more physical health problems (Lorenz, Wickrama, Conger, \& Elder, 2006; Sbarra, 2015), more frequent hospitalization (Nielsen, Davidsen, Hviid, \& Wohlfahrt, 2014), higher suicide rates (Corcoran \& Nagar, 2010), and greater mortality risk (Sbarra, 2015; Sbarra \& Nietert, 2009). Further, divorce has consistently been found to be associated with lower levels of psychological well-being (Bracke et al., 2010; Walid \& Zaytseva, 2011) and common correlates of divorce are mental health concerns (Kendler, Hettema, Butera, Gardner, \& Prescott, 2003), including higher levels of anxiety, depression, and somatization (Al-Krenawi \& Graham, 2004; Bracke et al., 2010; Breslau et al., 2011; Kendler et al., 2003; Metsä-Simola \& Martikainen, 2013; Monden et al., 2015; Symoens, Colman, \& Bracke, 2014; Thuen, 2000; Walid \& Zaytseva, 2011).

The comorbidity between anxiety, depression, and somatization has been found to be high (up to $55 \%$ ) (Barsky, Orav, \& Bates, 2005; Bekhuis, Boschloo, Rosmalen, \& Schoevers, 2015; De Waal, Arnold, Eekof, \& Van Hemert, 2004; Haug, Myklerun, \& Dahl, 2004; Henningsen, Zimmermann, \& Sattel, 2003; Löwe et al., 2008; Özen, Serhadli, Türkcan, \& Ülker, 2010; Rosmalen, Tak, \& De Jonge, 2011). The high comorbidity could be due to considerable overlap in 
the diagnostic criteria, treatment for, and conceptual understandings of depression, anxiety, and somatization (Kendell \& Jablensky, 2003; Löwe et al., 2008) and the fact that somatization and mood disorders traditionally have been considered a spectrum in which more somatic symptoms may indicate increased disorder severity (Özen et al., 2010). Further, research has shown associations in brain structure in individuals with depressive, anxious and somatoform symptoms (Besteher et al., 2017) suggesting possible neuroanatomical communalities between the three. However, to the knowledge of the authors, there have been no published studies assessing these three mental health outcomes concurrently in divorced populations.

Although divorce research consistently has documented adverse psychological- and physiological effects of divorce, it is important to point out that especially (but not only) psychological long term adaptation to divorce has been found to differ among divorcees as a function of personality, sociodemographic variables, and divorce characteristics (Perrig-Chiello, Hutchison, \& Morselli, 2015). Here, studies suggest that in the longer-term (i.e., 3+ years), most divorcees adapt quite well to divorce while approximately $20 \%$ of divorcees experience pronounced psychological problems and lower well-being even years after their divorce (see also Perrig-Chiello et al., 2015).

In divorce research, there has been a call for studies employing 'real-time' research (i.e., research investigating outcomes among divorcees shortly following their juridical divorce (e.g., Thuen, 2000)). This is mainly because there is reason to believe that many of the outcomes previously studied in divorce research (e.g., depression) are sensitive to a time effect, whereby symptoms/levels of the outcome studied naturally decline over time i.e., a 'time heals' effect (Hald, Ciprić, Sander, \& Strizzi, 2019; Thuen, 2000). Primarily due to legislative reasons, divorce research typically includes study samples where participants are either still married but separated and/or have been separated for a number of months before their juridical divorce and study inclusion. Consequently, little is known about the trajectories of these previously studied 
outcomes (anxiety, depression, somatization) among divorcees with little or no seperation periodes before juridical divorce.

As divorce is associated with adverse psychological effects there has been a call for scalable cost-effective evidence-based interventions that could reduce these effects (e.g., Bowers, Mitchell, Hardesty, \& Hughes, 2011; Salem et al., 2013). Both in the US and abroad, various divorce education programs have been established and their value is well-recognized (Bowers, Ogolsky, Hughes, \& Kanter, 2014; Schramm, Kanter, Brotherson, \& Kranzler, 2018; Turner, Kopystynska, Schramm, \& Higginbotham, 2019). Consequently, many states in the US mandate divorcees to participate in divorce education programs before their divorce can be legally finalized (Turner et al., 2019). Further, in Denmark, from April 2019, all divorcees with children under the age of 18 must complete a mandatory online learning module lasting approximately 30 minutes to obtain a legal divorce.

Because of easy and cheap access to the Internet and technological developments in the mobile industry (e.g., smartphones and tablets) over the last decade, some of these divorce education programs have expanded their face-to-face classes into online versions (see also Bowers et al., 2011; Turner et al., 2019). Although not 'born digital' these online interventions offer a number of advantages such as greater outreach to audiences that may otherwise be excluded from traditional face-to-face interventions, convenience, affordability, scalability, reduced stigmatization, self-monitoring of progress through the intervention, and the ability to expand contents and parental support beyond classroom or face-to-face interactions (Bowers et al., 2011; Greenberg, Fidler, \& Saini, 2019; Dennis \& Ebata, 2005). More generally, digital health interventions hold great potential as scalable tools to improve health by improving effectiveness, efficiency, accessibility, safety, and personalization (Andersson, Rozental, Titov, Dear, \& Carlbring, 2019). 
However, in the area of divorce research, very few digital intervention programs have been evaluated scientifically (Becher et al., 2018). To date and to the best knowledge of the authors, no online divorce intervention has been evaluated using a randomized controlled trial (RCT). On this basis, Bowers and colleagues (2011) wrote a convincing and comprehensive review and evaluation of the content of online educational programs targeting divorcing parents and concluded that scientific evaluations of these online programs were minimal to nonexistent. This is in contrast to face-to-face divorce interventions where RCT studies are more common and have shown that face-to-face interventions may improve a number of outcomes related to parenting skills and children's mental health (Greenberg et al., 2019).

For example, in a meta-analysis examining the effectiveness of court-affiliated face-toface education programs on co-parenting conflict, parent-child relationships, child well-being, parent well-being, and re-litigation, Fackrell and colleagues (2011) found that across 19 studies, including a treatment group and a no-treatment control group, the effect sizes were small to moderate $(d=0.19-0.61)$ with the overall effect being moderate in size $(d=0.39)$. However, Fackrell et al. (2011) also concluded that several of the studies suffered from important methodological shortcomings such as non-randomized control groups and short term follow-up. These conclusions were later supported in a more theoretical review of the development and current status of the parent education movement in the Family Courts in the US by Salem and colleagues (2013), who called for more rigorous designs and methodology, including more RCT studies, in evaluating the effectiveness of family divorce education programs. Finally, Schramm and McCaulley's (2012) compared the relative effectiveness of an in-person group-based divorce education program versus an identical online version of this program. They found that the online program was about as effective as the in-person program.

Although Schramm and McCaulley's (2012) evaluation provides a first and much-needed step in using scientific methodology to evaluate online interventions, the design still lacked the 
use of a control group as well as normed and validated measures allowing for comparisons of outcomes over time with general divorce- or background populations. While others have also attempted to take up the practice of intervention evaluation (e.g., Becher et al., 2018; Harold et al., 2016), these designs have continued to lack in key elements such as the use of appropriate control groups, longer follow-up times, and/or normed and validated outcome measures.

Consequently, longitudinal RCT studies using normed and validated outcome measures are highly needed in the area of family research pertaining to divorce (Bowers et al., 2011, 2014; Greenberg et al., 2019; Schramm et al., 2018; Schramm \& McCaulley, 2012; Turner et al., 2019) to better inform policymakers and clinicians about the effectiveness of online digital divorce interventions and programs (Andersson et al., 2019; Fackrell et al., 2011; Greenberg et al. 2019).

To address previous gaps in knowledge and with the aim of reducing already welldocumented elevated levels of depressive symptoms, in conjunction with the less well-studied outcomes of anxiety and somatization among divorcees, the present study presents the results of a one-year longitudinal RCT of a digital intervention including a large-scale sample of recently divorced Danish citizens. Specifically, the study aims to answer the following two research questions:

Research question 1. What is the effectiveness of the digital online intervention 'Cooperation after Divorce' (CAD) in reducing anxious, depressive, and somatization symptoms among divorcees?

Research question 2. How do symptoms of depression, anxiety, and somatization among Danish divorcees compare to the general Danish population one-year post juridical divorce?

\section{Method}

\section{Participants}

The sample comprised 1,856 recently divorced Danes (66.8\% women) with an average age of 45.32 years $(S D=8.66)$. On average participants completed the baseline survey 4.74 days $(S D$ 
$=7.10$ days) after they obtained their juridical divorce. Approximately $88 \%$ were first-time divorcees. The average marital duration was $12.74(S D=8.03$; range $0.00-51.76)$ years. The majority of the sample $(88.3 \%)$ were parents, with an average of $1.88(S D=0.985)$ children per participant. The average age of these children was 13.50 years $(S D=8.16)$. For further sample descriptions, please see Table 1.

Response-rates. Participants were invited to the study through e-mailed letters sent out by the Danish State Administration (DSA), who grants divorce decrees in Denmark. As the DSA is unable to provide the exact number of study links sent during the trial inclusion period (i.e., January 2016 to January 2018), we cannot provide the exact study response rate. Of those who agreed to study participation ( $\mathrm{N}=1,882), 26$ participants were excluded due to incomplete baseline questionnaires (i.e., those who did not report gender, reported to be married less than one day, or to have married the same year as they were born). Therefore, the final analytical sample comprised 1,856 participants (see also the Figure 1).

Representativeness of the final sample. In order to assess if those who elected to participate in the study significantly differed from the Danish population of divorcees, sociodemographic data for all people who divorced in Denmark during the study period was obtained from Statistics Denmark. The sample was representative in terms of age, income, and marriage duration. In the study sample, there were more female participants $\left(X^{2}(1, \mathrm{n}=1856)=208.45, p<\right.$ $0.001)$, more highly educated participants $\left(X^{2}(2, \mathrm{n}=1856)=1135.23, p<0.001\right)$, and on average participants had fewer previous divorces $(t(1855)=-8.47, p<0.001)$ than the Danish divorce population during the study period.

Randomization bias. A randomization schedule was set up so that, during the study inclusion period, participants were assigned sequentially over a two week period to either the intervention or control group resulting in a total of 27 recruitment rounds for the intervention group and 27 recruitment rounds for the control group (i.e., 108 weeks). The assignment schedule 
was blinded to the researchers during the inclusion period. This was done due to heavy media- and public policymaker interest for the intervention. This meant that, at certain times during the data collection process, the intervention received a lot of media coverage which may have influenced the likelihood of divorcees to join the study. Hence, this likely also explains the somewhat uneven allocation ratios (i.e., control group 44.5\%; intervention group 55.5\%). To determine if possible selection bias was produced during the randomized allocation into the intervention or the control group, the intervention and the control group were compared on all sociodemographic variables (gender, age at survey, education, income), divorce-related characteristics (times divorced, marriage duration, parenthood status, conflict degree with a former spouse), and relevant healthrelated variables (depression, anxiety, stress, and mental and physical health). No significant differences on any of the variables were found, indicating that the randomization was successful (for details, see Table 1).

Attrition rate. The initial study sample reduced in size in the intervention group by $72.1 \%$ from baseline (T1) $(n=1,050)$ to 3 months follow-up (T2) $(n=293)$, and in the control group by $70.2 \%$ from T1 $(n=832)$ to T2 $(n=248)$, but stabilized in subsequent follow-ups at 6 months (T3) and 12 months (T4) (intervention group: T3 $=254$ and T4 $=230$; control group: $\mathrm{T} 3=212$ and T4 =190). This attrition rate is consistent with the high dropout rates of longitudinal online eHealth studies (Donkin et al., 2011; Eysenbach, 2005; Geraghty, Torres, Leykin, Pérez-Stable, \& Muñoz, 2013).

Attrition bias. To determine if the attrition rate resulted in an attrition bias, multiple logistic regression analysis was performed to compare participants who dropped out after baseline to the rest of the sample using baseline information. Predictors were sociodemographic variables (group membership, gender, age at survey, education, income), divorce-related characteristics (times divorced, marriage duration, number of children, conflict degree with a former spouse), and mental and physical health indicators (depression, anxiety, somatization, 
stress, mental and physical health). It was observed that younger age $(\mathrm{AOR}=-0.996, p<0.05)$ and poorer physical health $(\mathrm{AOR}=0.953, p<0.01)$ predicted baseline drop-out. For the control group, no predictors were significant. To conservatively account for potential informative drop-out, all variables were included as controls in the main analyses. Thus, the study attrition bias was found to be modest and mostly fixable by statistical means. Further details are provided in the supplementary materials.

\section{Procedure}

These data are part of a 12-month longitudinal randomized controlled trial study (RCT) of the online intervention platform entitled 'Cooperation after Divorce' (CAD) that was initiated in November 2015 in collaboration with the Danish State Administration (DSA). The objective was to assess effects of the CAD intervention platform on well-studied adverse health outcomes associated with divorce. Outcome measures included health-related quality of life, perceived stress, anxiety, depression, hostility, somatization, parent reports of children's health-related quality of life, sick days, and days of absence from work. Throughout the study period spanning from January 2016 to January 2018, Danish citizens who wanted to divorce initiated their legal divorce and separation procedures by submitting an application to the DSA. Divorce was granted immediately when there was mutual agreement to the divorce between the spouses. If there were disagreements to divorce terms or to the divorce itself, a six-month separation period was initiated, after which legal divorce was granted even if a mutual agreement had not been reached; this occurred in only $30 \%$ of cases, according to the DSA. For this study, the DSA sent information on the study and an invitation letter to participate along with their divorce decree. People who decided to participate used the digital link enclosed, created an account on the CAD website, provided informed consent, responded to the baseline survey and were then randomized to either the intervention or the control group following the randomization schedule described above (see also the section on selection bias). Participants were sent three follow-up 
questionnaires at 3-, 6-, and 12-months post-divorce to the email they had provided when responding to the baseline questionnaire.

Responses were anonymized and stored in anonymous form on a secure server. The study was approved by the Danish Data Protection Agency. The study was exempt from further ethical evaluations following the rules and regulations as set forth by the Scientific Ethical Committees of Denmark.

\section{Measures \& Materials}

Sociodemographic variables. The following sociodemographic variables were assessed: a) Gender was coded $0=$ "Male" and $1=$ "Female"; b) Age at divorce was measured in years and months; c) Education level was assessed by the highest level of completed formal education. Subsequently, these responses were transformed into three categories: $0=$ "Low level of education" (e.g. primary school, high school, business high school, vocational education), $1=$ "Medium level of education" (e.g. medium-cycle tertiary education, bachelor's degree) and $2=$ "High level of education" (e.g. master's degree or higher); d) Monthly income was reported on a nine-point scale with 10,000 DKK intervals (app. 1,500 USD intervals), from 0 = "below 10,000 DKK" (i.e., below 1,500 USD) to $8=$ "more than 80,000 DKK" (i.e., approximately 12,000 USD) and subsequently recoded into: $0=$ "Below national average", $1=$ "National average" and $2=$ "Above national average".

Marriage and divorce-related variables. We also assessed a variety of marriage and divorce-related variables: a) Number of divorces was obtained by asking participants, "How many times have you divorced?" with response options including $0=$ "One time", $1=$ "Two times", $2=$ "Three times" and 3 = "More than three times"; b) Marriage duration was calculated in years and months from the marital date to the juridical divorce date; c) Legal divorce duration was calculated in months from the juridical divorce date to the baseline survey response date; d) Parenthood status was determined by asking the number of children the participants had; e) 
Children's age was calculated from the birthdate of the children as provided by participants and to the baseline survey response date; f) Degree of conflict was assessed by the 6-item self-report Divorce Conflict Scale (DCS). The DCS assesses six dimensions of divorce-related conflict: communication, co-parenting, global assessment of former spouse, negative and pervasive negative exchanges and hostile, insecure emotional environment, self-perceived conflict (Hald, Strizzi, Ciprić, \& Sander, 2019). The internal consistency of the scale was high $(\alpha=0.88)$.

Health Indicators. We assessed various mental and physical health indicators that were used in the randomization bias analyses. Specifically, a) Physical Health and b) Mental Health were assessed using the SF-36 (Ware, Snow, Kosinski, \& Gandek, 1993); while c) Stress was measured using the Danish version of the Perceived Stress Scale (PSS; Eskildsen et al., 2015).

Depressive, anxiety and somatization symptoms were assessed using the appropriate subscales from the Danish version of the Symptom Checklist-90-Revised (SCL-90-R; Derogatis, 2009). The measurement of depression included 13 items while anxiety and somatization included 10 and 12 items respectively. For each item, the response scale included a 5 point Likert scale with response options $0=$ not at all and $4=$ very much. Higher scores indicate more symptoms of depression, anxiety, and somatization. All three scales demonstrated high internal consistency ( $\alpha$ $=0.87-0.95)$ at all four data collection waves and stability over time $(r=0.55-0.75)$.

The CAD intervention. The CAD digital intervention platform is comprised of 17 digital learning modules and supporting functionalities including a debate forum and an opportunity to interact with divorce experts (see also supplemental materials). CAD is accessed online from a computer, mobile device, or tablet. Each module takes approximately 30-60 minutes to complete. The contents of the modules target well-known themes often relevant to divorcees. These challenges are arranged into three main areas and divided into 17 divorce-related themes (learning modules). These are: 
Main area 1: Yourself, which covers six themes: a) how divorce affects you, b) let go and forgive, c) coping with grief, d) ways to deal with negative thoughts, e) how to handle crisis, and f) anger management.

Main area 2: The Children, which covers the following four themes: a) how children experience divorce, $b$ ) understanding children's feelings and reactions, c) putting children's needs first, and d) how to communicate with children about divorce.

Main area 3: Co-parenting, which comprises seven themes: a) avoiding typical pitfalls, b) making clear agreements, c) how to get through holidays and birthdays, d) roads to good coparenting communications, e) dealing with conflicts, f) how to create good co-parental cooperation, and g) find common ground in child rearing.

The overall objective of the modules is to provide a combination of knowledge and tools designed to increase the likelihood of learning relevant coping strategies and adequate behavioral changes and behaviors. Accordingly, each module includes psychoeducation, exercises, questions, and/or dilemmas. Two core communication and interaction principles are applied throughout the intervention and all of the 17 learning modules: 1) A minimum of text is used and content consisted of 'rich media' such as video, animation, illustrations, pictures, and voice-overs 2) User activation so that users are activated every $2-5$ minutes with exercises, questions, and/or dilemmas. Given that divorce is a heterogeneous process and the experience of divorce is different for each individual, participants choose the modules that are most relevant to them, thus ideal dosage cannot be calculated as each individual's experience with divorce is different. In the current study participants on averaged used 4.27 modules (SD 2.94). For more detailed descriptions of CAD, please see the supplementary materials.

\section{Data analyses}

We analyzed and report results on an intention to treat (ITT) basis and accordingly all participants who are randomized are included in the statistical analysis regardless of what 
treatment they received (Gupta, 2011). Along with the assessment of attrition bias (please see participant section), any data available from participants were included with a full information maximum likelihood (FIML) estimation approach in order to protect against any informative missing pattern (Little, 2013). This enables robustness of the longitudinal estimates.

We conducted linear mixed effect model analyses using the lme4 package for ' $R$ ' version 3.5.3. The main exposure variables were measurement time points, group allocation and their interaction. Both time point and group membership were treated as categorical variables. Thus, we were able to analyze the full response trajectory using all participants and with an unrestricted time effect. Treatment effects are quantified as mean differences at 3,6 and 12-months. Treatment effects at each time point are also reported as Cohen's $(d)$ effect size as inferred from the model fit (i.e., the mean difference divided by the standard deviation on the considered outcome). We tested for any effect of the intervention by a likelihood ratio test for no effect of group assignment at any time point. Individual differences in initial levels of the outcomes were accounted for by a random intercept. As mentioned previously we repeated the analyses, controlling for gender, age, education, income, times divorced, number of children, duration of marriage, conflict degree, physical and mental health, and stress levels, to ensure that attrition did not influence the results of the analyses.

To further assess the effects of the intervention, depression, anxiety, and somatization scores at the 12-month follow-up for the intervention and control groups were compared with comparable normative data from a Danish national representative study sample (Derogatis, 2009) using one-sample t-tests.

\section{Results}

At basline (i.e. T1), the average score on depressive symptoms was 1.38 for men $(S D=$ $0.94 ;$ median $=1.23 ;$ mode $=0 ;$ range $=0-4)$ and 1.51 for women $(S D=0.94 ;$ median $=1.38 ;$ mode $=1 ;$ range $=0-4)$. The average score on anxiety symptoms was 0.82 for men $(S D=0.77$; 
median $=0.60 ;$ mode $=0 ;$ range $=0-4)$ and 0.94 for women $(S D=0.80 ;$ median $=0.70 ;$ mode $=$ 0 ; range $=0-4)$. The average score on somatization symptoms was 0.61 for men $(S D=0.64$; median $=0.42 ;$ mode $=0 ;$ range $=0-4)$ and 0.87 for women $(S D=0.73 ;$ median $=0.67 ;$ mode $=$ $0 ;$ range $=0-4)$

Table 2 provides data pertaining to research question 1 investigating the treatment effect of the CAD intervention on symptoms of depression, anxiety, and somatization using linear mixed effect models. As expected the intervention and the control groups did not differ at baseline. The overall treatment effect was found to be highly significant at $p<.0001$ for all three outcomes. Accordingly, the intervention group showed significantly lower rates of symptoms of depression, anxiety, and somatization at each of the time points investigated compared to the control group (i.e., at 3, 6 and 12 months post baseline). These results were found to be robust even when controlling for the (measured) imbalances in drop-out which confirms that attrition did likely not influence the outcomes of the results. In fact, it was found that these controlling procedures increased the effect of the CAD solution on the outcomes studied (see also Table 2). The magnitude of this decline (i.e. the differences in symptoms of depression, anxiety, and somatization between the intervention and the control group) was found to be large in effect size (Depression: Cohen's $(d)$ at 3 month $=1.349$ to-1.745 at 12 months; Anxiety: Cohen's $(d)$ at 3 months $=0.812$ to 0.997 at 12 months; Somatization: Cohen's $(d)$ at 3 months $=0.87$ to 0.78 at 12 months (see also Table 2 and Figure $2+3$ ). Within the control group, analyses also reveal a significant decline in symptom levels across outcomes consistent with a time heals effect (see also the Introduction and Table 2).

To further inspect the intervention effect, and given that women tend to report higher depressive symptoms than men (Olsen, Mortensen, \& Bech, 2006), a 3-way interaction between gender, group assignment, and treatment was included in the analyses. However, this interaction 
was found to be insignificant $(p>.05)$ suggesting that the treatment effect of the CAD solution on symptoms of depression, anxiety, and somatization did not differ between men and women.

\section{Norm Comparisons}

To investigate the second research question of the study we compared symptoms of depression, anxiety, and somatization in the study sample at time point 4 (i.e., at the 12 -month follow up) with Danish normative data (Derogatis, 2009) using one-sample t-tests. The results are depicted in Figure 3.

Compared to the general Danish male and female population, men and women in the control group reported significantly more symptoms of depression $($ men $t(45)=4.915, p<.001$; women $t(127)=7.409, p<.001)$, anxiety $(\operatorname{men} t(45)=2.701, p=.010 ;$ women $t(127)=5.104, p$ $<.001)$, and somatization $(\operatorname{men} t(45)=2.198, p=.033$; women $t(127)=3.204, p=.002)$ one year post juridical divorce. The magnitude of these differences was found to be moderate to large in effect size (Cohen's $d=0.57-1.47)$.

Compared to the general Danish female population, women in the intervention group reported significantly more depressive symptoms $(t(131)=2.017, p=.040, d=.36)$ but fewer symptoms of somatization $(t(131)=-2.210, p=.029, d=.39)$ one year post juridical divorce while no significant differences in symptoms of anxiety were found $(p=.852)$. Compared to the general Danish male population, men in the intervention group reported significantly fewer symptoms of anxiety $(t(79)=-2.400, p=.019, d=.54)$ and somatization $(t(79)=-4.186, p<$ $.001, d=.94$ ) one year post juridical divorce while no significant differences in symptoms of depression were found $(p=.58)$.

Following generally recommended cut-off values for risk of suffering from a psychiatric diagnosable case of depression, anxiety and somatization in Denmark ( $t$-score $>=63$; Olsen et al., 2006), we found that a considerably higher proportion of participants in the control group scored equal to or higher than the recommended cut-off values than in the general population 
(depression: men $=42 \%$, women $=32 \%$; anxiety: men $=26 \%$, women $=23 \%$; somatization: men $=27 \%$, women $=17 \%$ ). In comparison, in the intervention group, the proportion of participants who scored equal to or higher than the recommended cut-off values were on par with the 5-15\% found in the general Danish population (depression: men $=13 \%$, women $=10 \%$; anxiety: men $=$ $9 \%$, women $=9 \%$; somatization: men $=5 \%$, women $=7 \%$ )

\section{Discussion}

Responding to calls for evidence-based online interventions in the area of divorce, the current study tested effects of the online intervention platform Cooperation after Divorce (CAD) on symptoms of depression, anxiety, and somatization among Danish divorcees using an RCT study design. Using normed and validated outcome measures, the study found that CAD significantly reduced symptoms of anxiety, depression, and somatization among divorcees over a one-year period compared with care-as-usual. Across gender, the magnitude of these effects was found to be large in size. Further, controlling for attrition and possible selective drop-out made no difference to the conclusions underlining the robustness of the results and the ability of the intervention to reduce symptoms of depression, anxiety, and somatization over a one year period.

The study findings corroborate earlier meta-analytic RCT findings on face-to-face programs, which have found court-affiliated face-to-face education programs effective across a number of domains including parental well-being (see also Fackrell et al., 2011) and shows that in the area of divorce-related anxiety, depression, and somatization, online intervention platforms may be equally effective. In fact, in the current study, the effectiveness of the CAD intervention on symptoms of depression, anxiety and somatization generally exceeded those previously found in RCT studies on court-affiliated face-to-face education programs on parental well-being (Fackrell et al., 2011).

Research generally suggests heterogeneity in trajectories of divorce-related depression (see also Malgaroli et al., 2017) and especially among those divorcees highest in depression, 
successful interventions are important due to the detrimental effects of depression on outcomes such as psychological well-being, quality of life, and parental ability (da Silva Lima \& de Almeida Fleck, 2007; Wilson \& Durbin, 2010). Accordingly, in regards to depression, this finding indicates significant human and public health benefits of the intervention platform even among those divorcees most affected by the divorce. There has been less research into the trajectories of symptoms of anxiety and somatization following divorce. The results of this study also showed significantly lower rates of symptoms of anxiety, and somatization in the intervention group as compared to the control group at each time point measured over the one year trial period. Further, the levels of these symptoms in the intervention group were generally comparable to those of the general population one year post divorce.

Although, these results strongly indicate that the CAD intervention may be effective in reducing symptoms of depression, anxiety and somatization, it should be noted that self-reports of physical health were predictive of study attrition for both the intervention and control groups. Accordingly, participants with more somatic symptoms may have had a higher likelihood of dropping out which may partially explain the lower outcome scores one year post-divorce as the conceptualization of the spectrum of severity of these disorders often overlap with measurements of physical health (Özen et al., 2010). Further, the effect of the intervention may also be accelerated by the inclusion of highly distressed individuals as indicated by the elevated levels of symptoms of depression, anxiety, and somatization at baseline and thus essentially prone to self selection biases. In this regard, couple research has indicated that effect sizes may double in size when interventions are targeted towards those individuals who experienced the most distress or those who begin the intervention with difficulties in the domain studied (see also Doss et al., 2016). Finally, the intervention is given very close to the juridical time of divorce in a sample who on average have had little or no separation time prior to their juridical divorce. Accordingly, the need for help may be especially pronounced at this time and divorcees more susceptible to the 
help given all of which may accerlerate the intervention effect. This is supported by the finding that the largest reduction in all three outcome symptoms were within the first three months following study inclusion.

The study showed that over time symptoms of depression, anxiety, and somatization in the control group also reduced - just not as much as in the intervention group. Theoretically, these results indicate a 'time heals effect' which is a central contention of one of the most cited theories in the area of stress and divorce namely the Divorce-Stress-Readjustment theory (DSR) which propose that time heals most divorce-related stress (Amato, 2000). Further, the results also support existing research on long term effects (i.e., 3+ years) of divorce which indicates that the majority (approximately 80\%) of divorces in the longer term adjust well to their divorce (see also Perrig-Chiello et al., 2015). Nonetheless, the results also showed that at one year post-divorce, the control group still had considerably elevated levels of symptoms of depression, anxiety, and somatization compared to the general population. This indicates that the $\mathrm{CAD}$ intervention may accelerate the speed of recovery to the 'symptom population norm' for depression, anxiety, and somatization.

One central limitation of the study design is its inability to clearly establish the mediation factors of the CAD-solution. This has mainly to do with the decision to allow participants to selfselect both the modules participants individually perceived as most relevant to them as well as the time used engaging them (see also the Method section as well as the Supplementary materials). However, we believe that the effectiveness of the CAD intervention platform in reducing anxious, depressive, and somatization symptoms among divorcees could be due to some of the previously proposed advantages of digital solutions reviewed in the Introduction. Specifically, by being a digital platform, members of the intervention group could access the content repeatedly and ondemand at their convenience, which could have increased usage of, satisfaction with, and exposure to the intervention material (Andersson et al., 2019; Dennis \& Ebata, 2005; Turner et al., 
2019). Further, participants could tailor their usage to their individual needs which may prove key in successful online divorce interventions as divorcees' needs may differ or change substantially during their first year post-divorce (Kołodziej-Zaleska \& Przybyła-Basista, 2016; Malgaroli et al., 2017; Symoens, Bastaits, Mortelmans, \& Bracke, 2013). Finally, the content of the intervention platform targets well-known and studied challenges that divorcees face as well as provide guidance for attitudinal and behavioral change to better cope with these. This includes communication with their former spouse, understanding common emotions and reactions to divorce among divorcees and their children, and co-parenting strategies. Exposure to materials related to these topics may foster self-efficacy, knowledge, and new or improved coping abilities which may reduce symptoms of depression, anxiety, and somatization (Schramm et al., 2018; Weiss, Francis, Senf, Heist, \& Hargraves, 2006). Such themes are also relevant in clinical settings where the CAD intervention may add as supplement to face-to-face interventions and be applicable to a wider range of mental health outcomes than studied here.

When evaluating the results of this study the following limitations should be taken into account. Results could be influenced by a general recruitment self-selection bias by which individuals with more symptoms of anxiety, depression, and somatization could be overrepresented, seeking help to relieve their symptoms. Given the nature of this study, it is impossible to ascertain the nature of the self-selection bias and thus the results must be interpreted with caution. The high attrition rate, though comparable to other studies (Cugelman, Thelwall, \& Dawes, 2011; Geraghty et al., 2013), could have introduced an attrition bias even if we found only two significant differences in the comprehensive array of variables investigated between those who completed all follow-ups and those who only completed the baseline questionnaire. Therefore, the results may not be generalizable across divorce populations. Moreover, true to its aim (research questions), the study does not investigate possible moderators of the intervention effect, besides gender, such as sociodemographic variables, divorce characteristics or other 
individual differences (Kołodziej-Zaleska \& Przybyła-Basista, 2016; Malgaroli et al., 2017; Symoens et al., 2013). Such investigations would be a welcome addition to further qualify the study findings. Finally, we were unable to determine if both partners in a prior marriage participanted in the study. This may affect the data power and independence of data in the study.

\section{Conclusions}

Using an RCT study design and a large sample of recently divorced Danes, the study found that the digital divorce intervention 'CAD' was highly effective in reducing symptoms of anxiety, depression, and somatization during the first year post juridical divorce compared to careas-usual. Further, at the one-year follow-up, it was found that the intervention significantly reduced symptoms of depression, anxiety, and somatization to a level close to or below the general population norm. As the intervention is digital and available online it is easily accessible and the set-up of the solution makes it scalable to large population sizes at low costs. Further, the solution offers individually tailored interactions to meet the relevant needs of divorcees and their families at a convenience and time that suit them and their everyday life. 


\section{References}

Al-Krenawi, A., \& Graham, J. (2004). Somatization among Bedouin-Arab women: Differentiated by marital status. Journal of Divorce \& Remarriage, 42(1-2), 131-143. http://dx.doi.org/10.1300/J087v42n01_06

Andersson, G. F., Rozental, A., Titov, N., Dear, B., \& Carlbring, P. (2019). Internet-delivered psychological treatments: From innovation to implementation. World Psychiatry, 18(1), 2028. http://dx.doi.org/10.1002/wps.20610

Barsky, A.J., Orav, E.J., \& Bates, D.W. (2005) Somatization increases medical utilization and costs independent of psychiatric and medical comorbidity. Archives of General Psychiatry, 62(8), 903-910. http://dx.doi.org/10.1001/archpsyc.62.8.903

Becher, E. H., Mcguire, J. K., McCann, E. M., Powell, S., Cronin, S. E., \& Deenanath, V. (2018). Extension-based divorce education: A quasi-experimental design study of the parents forever program. Journal of Divorce \& Remarriage, 59(8), 633-652. http://dx.doi.org/10.1080/10502556.2018.1466256

Bekhuis, E., Boschloo, L., Rosmalen, J., \& Schoevers, R. (2015). Differential associations of specific depressive and anxiety disorders with somatic symptoms. Journal of Psychosomatic Research, 78(2), 116-122. http://dx.doi.org/10.1016/j.jpsychores.2014.11.007

Besteher, B., Gaser, C., Langbein, K., Dietzek, M., Sauer, H., \& Nenadić, I. (2017). Effects of subclinical depression, anxiety and somatization on brain structure in healthy subjects. Journal of Affective Disorders, 215, 111-117. http://dx.doi.org/10.1016/j.jad.2017.03.039

Bowers, J. R., Mitchell, E. T., Hardesty, J. L., \& Hughes, R. (2011). A review of online divorce education programs. Family Court Review, 49(4), 776-787. http://dx.doi.org/10.1111/j.1744$\underline{1617.2011 .01413 . x}$ 
Bowers, J. R., Ogolsky, B. G., Hughes, R., \& Kanter, J. B. (2014). Coparenting through divorce or separation: A review of an online program. Journal of Divorce \& Remarriage, 55(6), 464484. http://dx.doi.org/10.1080/10502556.2014.931760

Bracke, P., Colman, E., Symoens, S., \& Van Praag, L. (2010). Divorce, divorce rates, and professional care seeking for mental health problems in Europe: A cross-sectional populationbased study. BMC Public Health, 10(1), 224. http://dx.doi.org/10.1186/1471-2458-10-224

Breslau, J., Miller, E., Jin, R., Sampson, N. A., Alonso, J., Andrade, L. H., . . Fukao, A. (2011). A multinational study of mental disorders, marriage, and divorce. Acta Psychiatrica Scandinavica, 124(6), 474-486. http://dx.doi.org/10.1111/j.1600-0447.2011.01712.x

Center for Disease Control and Prevention, 2016. Provisional number of marriages and marriage rate: United States, 2000-2016. Retrieved from: https://www.cdc.gov/nchs/data/dvs/national_marriage_divorce_rates_00-16.pdf

Corcoran, P., \& Nagar, A. (2010). Suicide and marital status in Northern Ireland. Social Psychiatry and Psychiatric Epidemiology, 45(8), 795-800. http://dx.doi.org/10.1007/s00127$\underline{009-0120-7}$

Cugelman, B., Thelwall, M., \& Dawes, P. (2011). Online interventions for social marketing health behavior change campaigns: A meta-analysis of psychological architectures and adherence factors. Journal of Medical Internet Research, 13(1), e17. http://dx.doi.org/10.2196/jmir.1367 da Silva Lima, A. F. B., \& de Almeida Fleck, M. P. (2007). Subsyndromal depression: An impact on quality of life? Journal of Affective Disorders, 100(1-3), 163-169. http://dx.doi.org/10.1016/j.jad.2006.10.010

Dennis, S., \& Ebata, A. (2005). Family life education on the technological frontier. In S. F. Duncan \& H. W. Goddard (Eds.), Outreach in family life: Principles and practices for effective family life outreach education (pp. 180-219). Thousand Oaks, CA: Sage. 
Derogatis, L. R. (2009). Symptom Checklist-90-R (Danish Version). Bloomington, MN: NCS Pearson, Inc.

De Waal, M., Arnold, I., Eekhof, J., \& Van Hemert, A. (2004). Somatoform disorders in general practice: Prevalence, functional impairment and comorbidity with anxiety and depressive disorders. The British Journal of Psychiatry, 184, 470-476. http://dx.doi.org/10.1192/bjp.184.6.470

Donkin, L., Christensen, H., Naismith, S., Neal, B., Hickie, I., \& Glozier, N. (2011). A systematic review of the impact of adherence on the effectiveness of e-therapies. Journal of Medical Internet Research, 13(3), E52. http://dx.doi.org/10.2196/jmir.1772

Doss, B. D., Cicila, L. N., Georgia, E. J., Roddy, M. K., Nowlan, K. M., Benson, L. A., \& Christensen, A. (2016). A randomized controlled trial of the web-based OurRelationship program: Effects on relationship and individual functioning. Journal of consulting and clinical psychology, 84(4), 285-296. http://dx.doi.org/10.1037/ccp0000063

Eskildsen, A., Dalgaard, V., Nielsen, K., Andersen, J., Zachariae, R., Olsen, L., \& Christiansen, D. (2015). Cross-cultural adaptation and validation of the Danish consensus version of the 10item Perceived Stress Scale. Scandinavian Journal of Work, Environment \& Health, 41(5), 486-490. http://dx.doi.org/10.5271/sjweh.3510

European Commission (2015). Demography Report. Luxembourg: Publications Office of the European Union.

Eysenbach, G. (2005). The law of attrition. Journal of Medical Internet Research, 7(1), E11. http://dx.doi.org/10.2196/jmir.7.1.e11

Fackrell, T., Hawkins, A., \& Kay, N. (2011). How effective are court-affiliated divorcing parents education programs? A meta-analytic study. Family Court Review, 49(1), 107-119. http://dx.doi.org/10.1111/j.1744-1617.2010.01356.x 
Geraghty, A., Torres, L., Leykin, Y., Pérez-Stable, E., \& Muñoz, R. (2013). Understanding attrition from international internet health interventions: A step towards global eHealth. Health Promotion International, 28(3), 442-452. http://dx.doi.org/10.1093/heapro/das029

Greenberg, L. R., Fidler, B. J., \& Saini, M. A. (Eds.). (2019). Evidence-informed interventions for court-involved families: Promoting healthy coping and development. New York, NY: Oxford University Press.

Gupta, S. (2011). Intention-to-treat concept: A review. Perspectives in Clinical Research, 2(3), 109-112. http://dx.doi.org/10.4103/2229-3485.83221

Hald, G. M., Ciprić, A., Sander, S., \& Strizzi, J. M. (2019). Anxiety and depression among recently divorced individuals. Unpublished manuscript.

Hald, G. M., Strizzi, J., Ciprić, A., \& Sander, S. (2019). The divorce conflict scale. Journal of Divorce and Remarriage, http://dx.doi.org/10.1080/10502556.2019.1627150

Harold, G., Acquah, D., Sellers, R., \& Chowdry, H. (2016). What works to enhance inter-parental relationships and improve outcomes for children. Retrieved from https://core.ac.uk/download/pdf/74381020.pdf

Haug, T. T., Mykletun, A. A., \& Dahl, A. (2004). The association between anxiety, depression, and somatic symptoms in a large population: The HUNT-II study. Psychosomatic Medicine, 66(6), 845-851. http://dx.doi.org/10.1097/01.psy.0000145823.85658.0c

Henningsen, P., Zimmermann, T., \& Sattel, H. (2003). Medically unexplained physical symptoms, anxiety, and depression: A meta-analytic review. Psychosomatic Medicine 65, 528-533. http://dx.doi.org/10.1097/01.PSY.0000075977.90337.E7

Kendell, R., \& Jablensky, A. (2003). Distinguishing between the validity and utility of psychiatric diagnoses. The American Journal of Psychiatry, 160(1), 4-12.

http://dx.doi.org/10.1176/appi.ajp.160.1.4 
Kendler, K., Hettema, J., Butera, F., Gardner, C., \& Prescott, C. (2003). Life event dimensions of loss, humiliation, entrapment, and danger in the prediction of onsets of major depression and generalized anxiety. Archives of General Psychiatry, 60(8), 789-796.

http://dx.doi.org/10.1001/archpsyc.60.8.789

Kołodziej-Zaleska, A., \& Przybyła-Basista, H. (2016). Psychological well-being of individuals after divorce: The role of social support. Current Issues in Personality Psychology, 4(4), 206216. http://dx.doi.org/10.5114/cipp.2016.62940

Little, T. D. (2013). Longitudinal structural equation modeling. New York, NY: Guilford Press.

Lorenz, F., Wickrama, K., Conger, R., \& Elder, G. (2006). The short-term and decade-long effects of divorce on women's midlife health. Journal of Health and Social Behavior, 47(2), 111125. http://dx.doi.org/10.1177/002214650604700202

Löwe, B., Spitzer, R., Williams, J., Mussell, M., Schellberg, D., \& Kroenke, K. (2008). Depression, anxiety and somatization in primary care: Syndrome overlap and functional impairment. General Hospital Psychiatry, 30(3), 191-199. http://dx.doi.org/10.1016/j.genhosppsych.2008.01.001

Malgaroli, M., Galatzer-Levy, I., \& Bonanno, G. (2017). Heterogeneity in trajectories of depression in response to divorce is associated with differential risk for mortality. Clinical Psychological Science, 5(5), 843-850. http://dx.doi.org/10.1177/2167702617705951

Mather, L., Blom, V., \& Svedberg, P. (2014). Stressful and traumatic life events are associated with burnout - A cross-sectional twin study. International Journal of Behavioral Medicine, 21(6), 899-907. http://dx.doi.org/10.1007/s12529-013-9381-3

Metsä-Simola, N., \& Martikainen, P. (2013). Divorce and changes in the prevalence of psychotropic medication use: A register-based longitudinal study among middle-aged Finns. Social Science \& Medicine, 94, 71-80. http://dx.doi.org/10.1016/j.socscimed.2013.06.027 
Monden, C., Metsä-Simola, N., Saarioja, S., \& Martikainen, P. (2015). Divorce and subsequent increase in uptake of antidepressant medication: A Finnish registry-based study on couple versus individual effects. BMC Public Health, 15(1), 158. http://dx.doi.org/10.1186/s12889$\underline{015-1508-9}$

Nielsen, N., Davidsen, R., Hviid, A., \& Wohlfahrt, J. (2014). Divorce and risk of hospitaldiagnosed infectious diseases. Scandinavian Journal of Public Health, 42(7), 705-711. http://dx.doi.org/10.1177/1403494814544398

Olsen, L. R., Mortensen, E. L., \& Bech, P. (2006). Mental distress in the Danish general population. Acta Psychiatrica Scandinavica, 113(6), 477-484. http://dx.doi.org/10.1111/j.1600-0447.2005.00743.x

Özen, E., Serhadli, Z., Türkcan, A., \& Ülker, G. (2010). Somatization in depression and anxiety disorders. Dusunen Adam, 23(1), 60-65.

Perrig-Chiello, P., Hutchison, S., \& Morselli, D. (2015). Patterns of psychological adaptation to divorce after a long-term marriage. Journal of Social and Personal Relationships, 32, 386405. https://doi.org/10.1177/0265407514533769

Rosmalen, J., Tak, L., \& De Jonge, P. (2011). Empirical foundations for the diagnosis of somatization: Implications for DSM-5. Psychological Medicine, 41(6), 1133-1142. https://doi.org/10.1017/S0033291710001625

Salem, P., Sandler, I., \& Wolchik, S. (2013). Taking stock of parent education in the family courts: Envisioning a public health approach. Family Court Review, 51(1), 131-148. http://dx.doi.org/10.1111/fcre.12014

Sbarra, D. A. (2015). Divorce and health: Current trends and future directions. Psychosomatic Medicine, 77(3), 227-236. http://dx.doi.org/10.1097/PSY.0000000000000168

Sbarra, D., \& Nietert, P. (2009). Divorce and death: Forty years of the Charleston Heart Study. Psychological Science, 20(1), 107-113. http://dx.doi.org/10.1111/j.1467-9280.2008.02252.x 
Schramm, D. G., Kanter, J. B., Brotherson, S. E., \& Kranzler, B. (2018). An empirically based framework for content selection and management in divorce education programs. Journal of Divorce \& Remarriage, 59(3), 195-221. http://dx.doi.org/10.1080/10502556.2017.1402656

Schramm, D. G., \& McCaulley, G. (2012). Divorce education for parents: A comparison of online and in-person delivery methods. Journal of Divorce \& Remarriage, 53(8), 602-617. http://dx.doi.org/10.1080/10502556.2012.721301

Symoens, S., Bastaits, K., Mortelmans, D., \& Bracke, P. (2013). Breaking up, breaking hearts? Characteristics of the divorce process and well-being after divorce. Journal of Divorce and Remarriage, 54(3), 177-196. http://dx.doi.org/10.1080/10502556.2013.773792

Symoens, S., Colman, E., \& Bracke, P. (2014). Divorce, conflict and mental health: How the quality of intimate relationships is linked to post-divorce well-being. Journal of Applied Social Psychology, 44(3), 220-233. doi:10.1111/jasp.12215

Thuen, F. (2000). Psychiatric symptoms and perceived need for psychiatric care after divorce. Journal of Divorce \& Remarriage, 34(1-2), 61-76. http://dx.doi.org/10.1300/J087v34n01_04

Turner, J. J., Kopystynska, O., Schramm, D. G., \& Higginbotham, B. (2019). Is one hour enough? Evaluating Utah's online divorce education course based on course length satisfaction. Journal of Divorce \& Remarriage, 60(7), 537-551. http://dx.doi.org/10.1080/10502556.2019.1586231

Vezzetti, V. C. (2016). New approaches to divorce with children: A problem of public health. Health Psychology Open, 3(2), 2055102916678105. http://dx.doi.org/10.1177/2055102916678105

Ware, J. E., Snow, K. K., Kosinski, M., \& Gandek, B. (1993). SF-36 health survey (SF-36): Manual and interpretation guide. Lincoln, RI: Quality Metric Incorporated.

Weiss, B. D., Francis, L., Senf, J. H., Heist, K., \& Hargraves, R. (2006). Literacy education as treatment for depression in patients with limited literacy and depression: A randomized 
controlled trial. Journal of General Internal Medicine, 21(8), 823-82 8.

http://dx.doi.org/10.1111/j.1525-1497.2006.00531.x

Wilson, S., \& Durbin, C. (2010). Effects of paternal depression on fathers' parenting behaviors: A meta-analytic review. Clinical Psychology Review, 30(2), 167-180.

http://dx.doi.org/10.1016/j.cpr.2009.10.007

Walid, M., \& Zaytseva, N. (2011). Which neuropsychiatric disorder is more associated with divorce? Journal of Divorce \& Remarriage, 52(4), 220-224.

http://dx.doi.org/10.1080/10502556.2011.556976 
Table 1. Descriptive Sample Characteristics of Recently Divorces Danes

\begin{tabular}{|c|c|c|c|c|c|}
\hline & \multicolumn{2}{|c|}{$\begin{array}{l}\text { Control } \\
(n=825)\end{array}$} & \multicolumn{2}{|c|}{$\begin{array}{c}\text { Intervention } \\
(n=1031)\end{array}$} & \multirow{2}{*}{$\begin{array}{c}\text { Group difference } \\
\text { test } \\
p\end{array}$} \\
\hline & $M / \%$ & $S D$ & $M / \%$ & $S D$ & \\
\hline Gender (women) & 67.8 & & 66.0 & & 0.442 \\
\hline Age & 45.26 & 8.58 & 45.37 & 8.72 & 0.786 \\
\hline \multicolumn{6}{|l|}{ Level of education } \\
\hline Low & 36.0 & & 36.6 & & \\
\hline Medium & 40.0 & & 35.1 & & 0.168 \\
\hline High & 24.0 & & 28.3 & & \\
\hline \multicolumn{6}{|l|}{ Income } \\
\hline Below average & 42.8 & & 38.7 & & \\
\hline Average & 42.4 & & 44.4 & & 0.842 \\
\hline Above average & 14.8 & & 16.9 & & \\
\hline Being a parent & 87.4 & & 88.9 & & 0.941 \\
\hline Number of children & 1.88 & 0.962 & 1.88 & 1.02 & 0.273 \\
\hline \multicolumn{6}{|l|}{ Times divorced } \\
\hline 1 time & 87.3 & & 88.1 & & \\
\hline 2 times & 10.9 & & 9.8 & & 0.842 \\
\hline 3 times & 1.5 & & 1.7 & & \\
\hline More than 3 times & 0.4 & & 0.4 & & \\
\hline Marriage duration & 12.63 & 8.07 & 12.83 & 7.99 & 0.593 \\
\hline Conflict degree $\left(0-27^{*}\right)$ & 13.7 & 4.84 & 13.79 & 4.99 & 0.696 \\
\hline Modules Used $\left(0-17^{*}\right)$ & 0.00 & 0.00 & 4.27 & 2.94 & \\
\hline \multicolumn{6}{|l|}{ Mental Health Indicators } \\
\hline Physical Health & 0.79 & 0.81 & 0.79 & 0.81 & 0.838 \\
\hline Mental Health & -1.55 & 1.36 & -1.56 & 1.35 & 0.936 \\
\hline Stress $\left(0-40^{*}\right)$ & 19.46 & 7.10 & 19.52 & 7.04 & 0.875 \\
\hline Somatization $\left(0-4^{*}\right)$ & 0.78 & 0.72 & 0.79 & 0.71 & 0.834 \\
\hline Anxiety $\left(0-4^{*}\right)$ & 0.88 & 0.78 & 0.91 & 0.80 & 0.459 \\
\hline Depression $\left(0-4^{*}\right)$ & 1.46 & 0.94 & 1.47 & 0.94 & 0.807 \\
\hline
\end{tabular}

Note. ${ }^{*}$ Possible value range. 
Table 2. Linear Mixed Effect Model Results for the Study Outcomes of Symptoms of Depression, Anxiety, and Somatization

\begin{tabular}{|c|c|c|c|c|c|c|}
\hline Variable & Estimate & Std. Error & Cohen's $d$ & Estimate & Std. Error & Cohen's $d$ \\
\hline \multicolumn{7}{|c|}{ Outcome: Depression } \\
\hline & \multicolumn{3}{|c|}{ Unadjusted } & \multicolumn{3}{|c|}{ Adjusted $^{\mathrm{d}}$} \\
\hline Intervention Group at Baseline & 0.011 & 0.044 & 0.020 & 0.007 & 0.029 & 0.024 \\
\hline Time effect -3 months ${ }^{b}$ & -0.010 & 0.045 & -0.013 & 0.007 & 0.040 & 0.023 \\
\hline Time effect -6 months ${ }^{b}$ & -0.077 & 0.048 & -0.105 & -0.070 & 0.043 & -0.224 \\
\hline Time effect -12 months ${ }^{b}$ & $-0.193^{* * *}$ & 0.051 & -0.261 & $-0.186^{* * *}$ & 0.046 & -0.595 \\
\hline Intervention group -3 months ${ }^{\text {ac }}$ & $-0.410^{* * *}$ & 0.061 & -0.556 & $-0.423^{* * *}$ & 0.054 & -1.349 \\
\hline Intervention group -6 months ${ }^{\mathrm{ac}}$ & $-0.515^{* * *}$ & 0.065 & -0.698 & $-0.504^{* * *}$ & 0.058 & -1.607 \\
\hline Intervention group -12 months $s^{a c}$ & $-0.543^{* * *}$ & 0.069 & -0.736 & $-0.547^{* * *}$ & 0.062 & -1.745 \\
\hline
\end{tabular}

Outcome: Anxiety

\begin{tabular}{|c|c|c|c|c|c|c|}
\hline Intervention Group at Baseline & 0.028 & 0.036 & 0.046 & 0.023 & 0.026 & 0.065 \\
\hline Time effect -3 months & -0.041 & 0.035 & -0.066 & -0.033 & 0.033 & -0.095 \\
\hline Time effect -6 months & $-0.087^{*}$ & 0.037 & -0.140 & $-0.086^{*}$ & 0.035 & -0.252 \\
\hline Time effect - 12 months & $-0.155^{* * *}$ & 0.040 & -0.249 & $-0.150^{* * *}$ & 0.038 & -0.438 \\
\hline Intervention group -3 months ${ }^{*}$ & $-0.270^{* * *}$ & 0.047 & -0.435 & $-0.279^{* * *}$ & 0.045 & -0.812 \\
\hline Intervention group -6 months ${ }^{*}$ & $-0.314^{* * *}$ & 0.050 & -0.505 & $-0.314^{* * *}$ & 0.048 & -0.913 \\
\hline Intervention group - 12 months ${ }^{*}$ & $-0.336^{* * *}$ & 0.054 & -0.542 & $-0.342^{* * *}$ & 0.051 & -0.997 \\
\hline \multicolumn{7}{|c|}{ Outcome: Somatization } \\
\hline Intervention Group at Baseline & 0.007 & 0.033 & 0.012 & 0.006 & 0.024 & 0.017 \\
\hline Time effect -3 months & $0.068^{*}$ & 0.030 & 0.116 & $0.084^{* *}$ & 0.029 & 0.251 \\
\hline Time effect -6 months & 0.027 & 0.032 & 0.045 & 0.027 & 0.031 & 0.080 \\
\hline Time effect -12 months & -0.052 & 0.035 & -0.089 & -0.043 & 0.033 & -0.130 \\
\hline Intervention group -3 months ${ }^{*}$ & $-0.285^{* * *}$ & 0.041 & -0.487 & $-0.290^{* * *}$ & 0.040 & -0.870 \\
\hline Intervention group -6 months ${ }^{*}$ & $-0.311^{* * *}$ & 0.044 & -0.531 & $-0.295^{* * *}$ & 0.042 & -0.886 \\
\hline Intervention group - 12 months ${ }^{*}$ & $-0.262^{* * *}$ & 0.047 & -0.448 & $-0.260^{* * *}$ & 0.045 & -0.780 \\
\hline
\end{tabular}

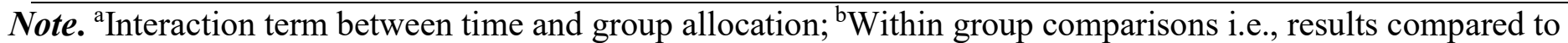
baseline; ${ }^{c}$ Between group comparisons i.e. the intervention group and the control group compared at each time point (3, 6, 12 months); ${ }^{\mathrm{d}}$ when controlling for the (measured) imbalances in drop-out; $* p<0.05, * * p<0.01, * * * p<0.001$. 
Table 2. Linear Mixed Effect Model Results for the Study Outcomes of Symptoms of Depression, Anxiety, and Somatization

\begin{tabular}{|c|c|c|c|c|c|c|}
\hline Variable & Estimate & Std. Error & Cohen's $d$ & Estimate & Std. Error & Cohen's $d$ \\
\hline \multicolumn{7}{|c|}{ Outcome: Depression } \\
\hline & \multicolumn{3}{|c|}{ Unadjusted } & \multicolumn{3}{|c|}{ Adjusted $^{\mathrm{d}}$} \\
\hline Intervention Group at Baseline & 0.011 & 0.044 & 0.020 & 0.007 & 0.029 & 0.024 \\
\hline Time effect -3 months ${ }^{b}$ & -0.010 & 0.045 & -0.013 & 0.007 & 0.040 & 0.023 \\
\hline Time effect -6 months $^{b}$ & -0.077 & 0.048 & -0.105 & -0.070 & 0.043 & -0.224 \\
\hline Time effect - 12 months ${ }^{b}$ & $-0.193^{* * *}$ & 0.051 & -0.261 & $-0.186^{* * *}$ & 0.046 & -0.595 \\
\hline Intervention group -3 months $\mathrm{s}^{\mathrm{ac}}$ & $-0.410^{* * *}$ & 0.061 & -0.556 & $-0.423^{* * *}$ & 0.054 & -1.349 \\
\hline Intervention group -6 months ${ }^{\mathrm{ac}}$ & $-0.515^{* * *}$ & 0.065 & -0.698 & $-0.504^{* * *}$ & 0.058 & -1.607 \\
\hline Intervention group - 12 months ${ }^{\mathrm{ac}}$ & $-0.543^{* * *}$ & 0.069 & -0.736 & $-0.547^{* * *}$ & 0.062 & -1.745 \\
\hline \multicolumn{7}{|c|}{ Outcome: Anxiety } \\
\hline Intervention Group at Baseline & 0.028 & 0.036 & 0.046 & 0.023 & 0.026 & 0.065 \\
\hline Time effect -3 months & -0.041 & 0.035 & -0.066 & -0.033 & 0.033 & -0.095 \\
\hline Time effect -6 months & $-0.087^{*}$ & 0.037 & -0.140 & $-0.086^{*}$ & 0.035 & -0.252 \\
\hline Time effect -12 months & $-0.155^{* * *}$ & 0.040 & -0.249 & $-0.150^{* * *}$ & 0.038 & -0.438 \\
\hline Intervention group - 3 months ${ }^{*}$ & $-0.270^{* * *}$ & 0.047 & -0.435 & $-0.279^{* * *}$ & 0.045 & -0.812 \\
\hline Intervention group -6 months ${ }^{*}$ & $-0.314^{* * *}$ & 0.050 & -0.505 & $-0.314^{* * *}$ & 0.048 & -0.913 \\
\hline Intervention group - 12 months ${ }^{*}$ & $-0.336^{* * *}$ & 0.054 & -0.542 & $-0.342^{* * *}$ & 0.051 & -0.997 \\
\hline \multicolumn{7}{|c|}{ Outcome: Somatization } \\
\hline Intervention Group at Baseline & 0.007 & 0.033 & 0.012 & 0.006 & 0.024 & 0.017 \\
\hline Time effect -3 months & $0.068^{*}$ & 0.030 & 0.116 & $0.084^{* *}$ & 0.029 & 0.251 \\
\hline Time effect -6 months & 0.027 & 0.032 & 0.045 & 0.027 & 0.031 & 0.080 \\
\hline Time effect -12 months & -0.052 & 0.035 & -0.089 & -0.043 & 0.033 & -0.130 \\
\hline Intervention group -3 months ${ }^{*}$ & $-0.285^{* * *}$ & 0.041 & -0.487 & $-0.290^{* * *}$ & 0.040 & -0.870 \\
\hline Intervention group -6 months ${ }^{*}$ & $-0.311^{* * *}$ & 0.044 & -0.531 & $-0.295^{* * *}$ & 0.042 & -0.886 \\
\hline Intervention group - 12 months ${ }^{*}$ & $-0.262^{* * *}$ & 0.047 & -0.448 & $-0.260^{* * *}$ & 0.045 & -0.780 \\
\hline
\end{tabular}

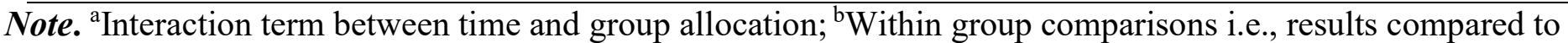
baseline; ${ }^{c}$ Between group comparisons i.e. the intervention group and the control group compared at each time point (3, 6, 12 months); ${ }^{\mathrm{d}}$ when controlling for the (measured) imbalances in drop-out; $* p<0.05, * * p<0.01, * * * p<0.001$. 
Figure 1. CONSORT Diagram

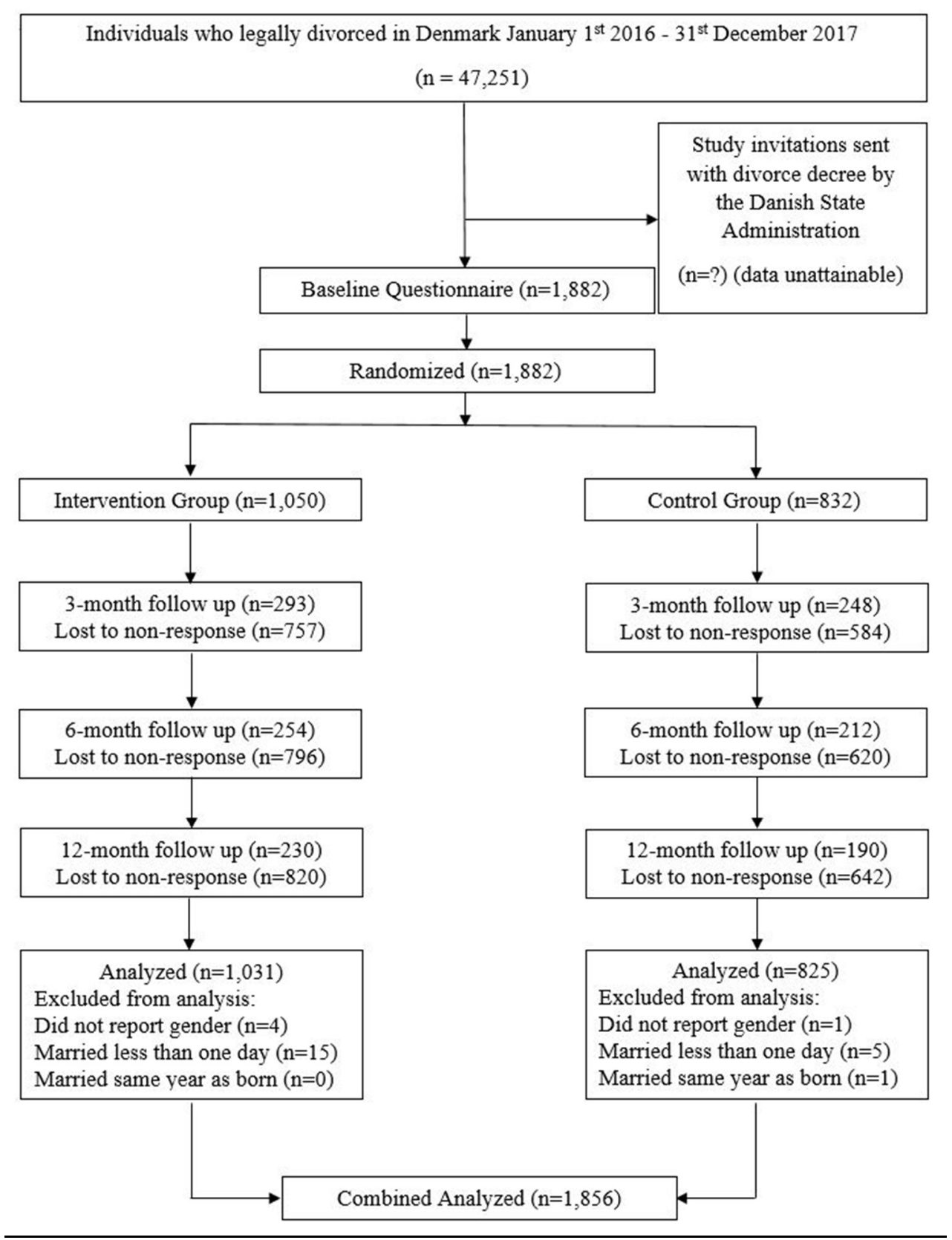


Figure 2. Depression, Anxiety and Somatization Mean Changes in Average Scores over Time as Estimated by Mixed Linear Effect Models and Adjusted for Attrition

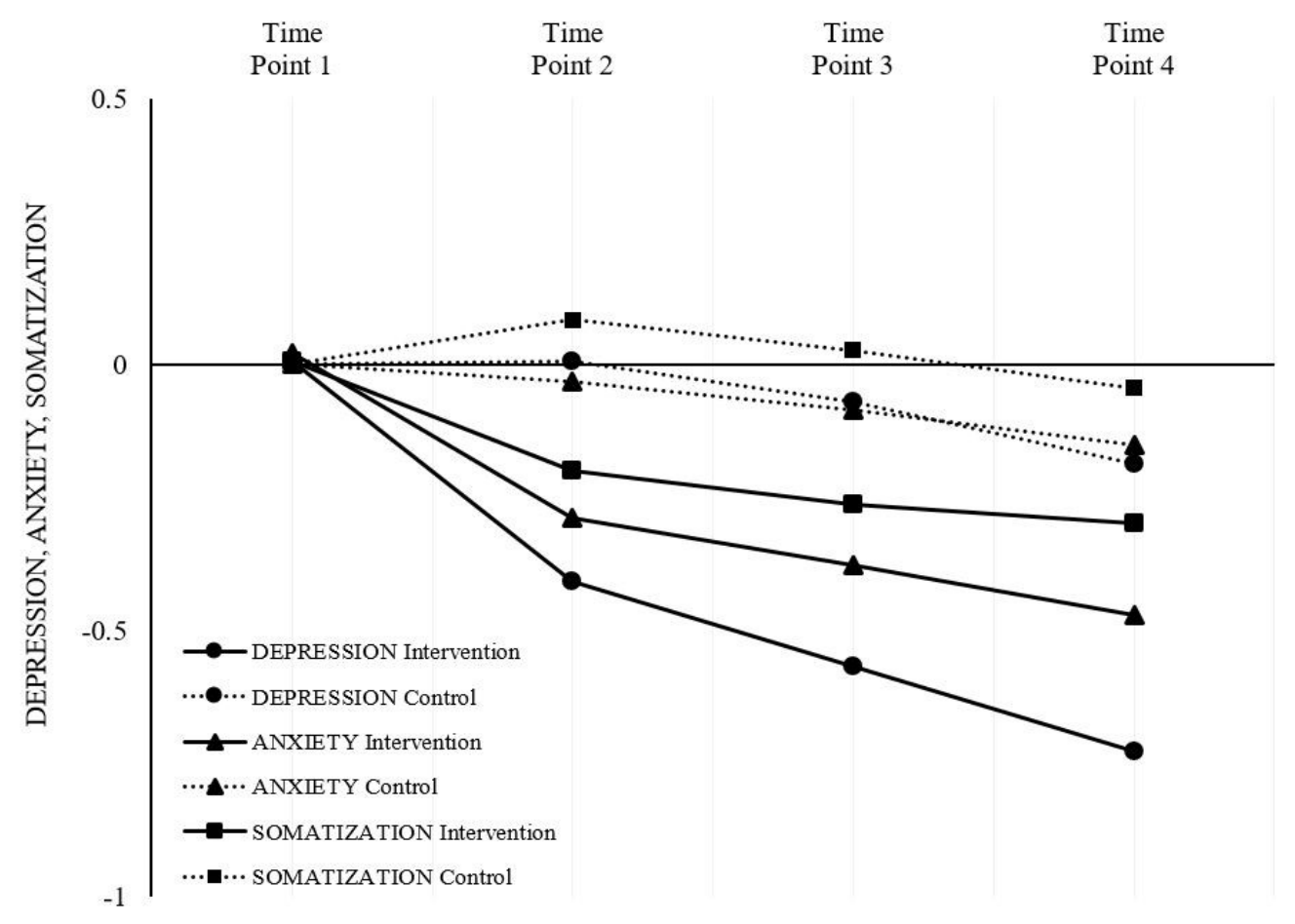

Note. Time Point 1 = baseline; Time Point 2 = 3-month follow-up; Time Point 3 =6-month follow-up; Time Point 4 = 12-month follow-up. 
Figure 3. Depression, Anxiety and Somatization Means at the 12-month Follow-up Compared with National Norm Data Stratified by Gender

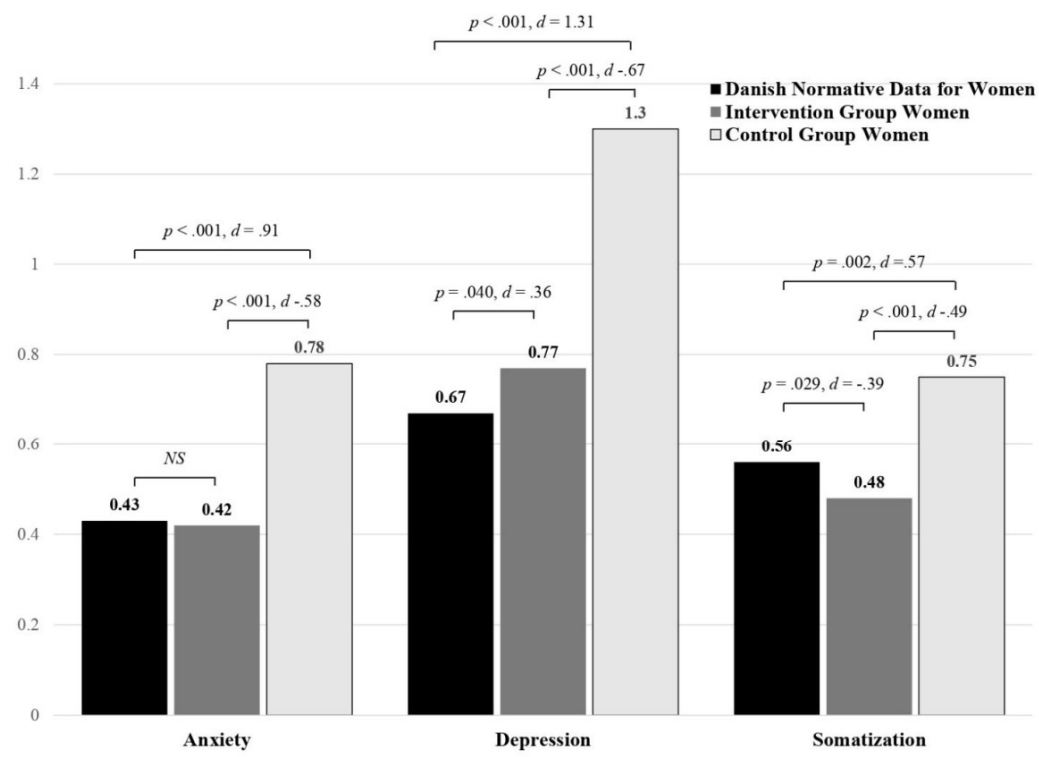

Figure 3a Anxiety, Depression and Somatization Means for Women at the 12-month Follow-up Compared with National Norm Data

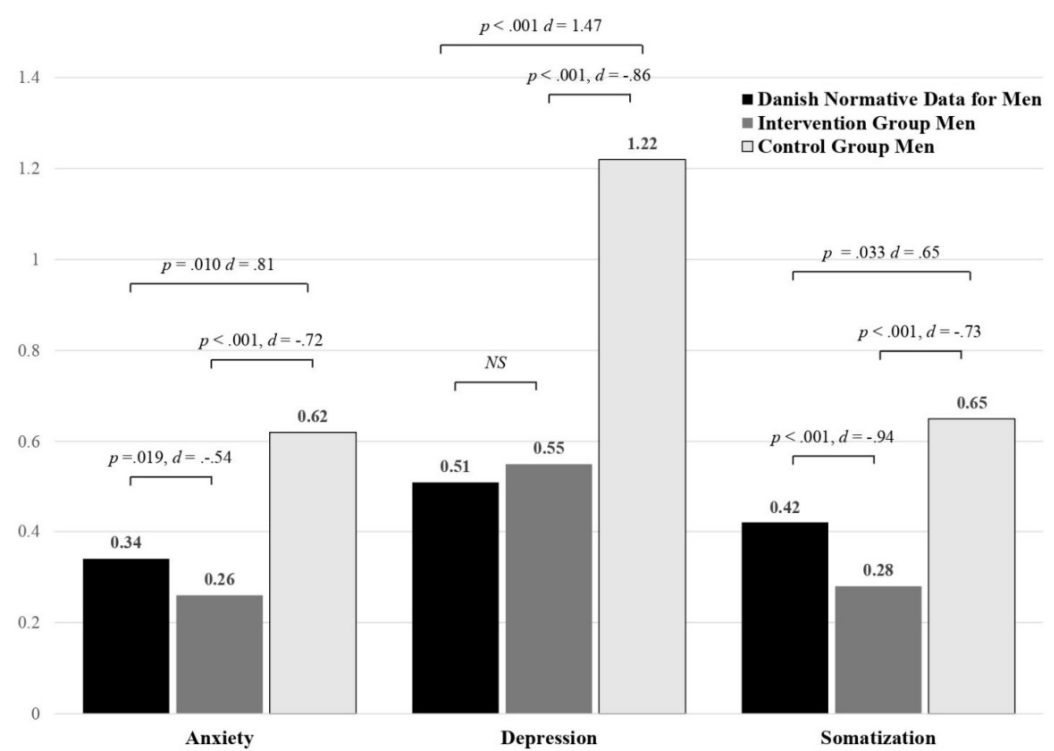

Figure 3b Anxiety, Depression and Somatization Means for Men at the 12-month Follow-up Compared with National Norm Data 


\section{Supplementary Materials 1.}

Description of the intervention. The CAD digital intervention consists of 17 digital learning modules and supporting functionality and contents, which are accessed online from a computer, mobile device or tablet. Each of the 17 digital learning modules, which are the core of the intervention, takes approximately 30-60 minutes to complete and users can freely choose which and how many learning modules they want to use and the time duration they want to spend engaging them.

The learning modules addresses challenges relevant for divorcees and are arranged into three main themes (A to C) presented in the flowchart below. The curriculum of each of the elements are described in the following table.

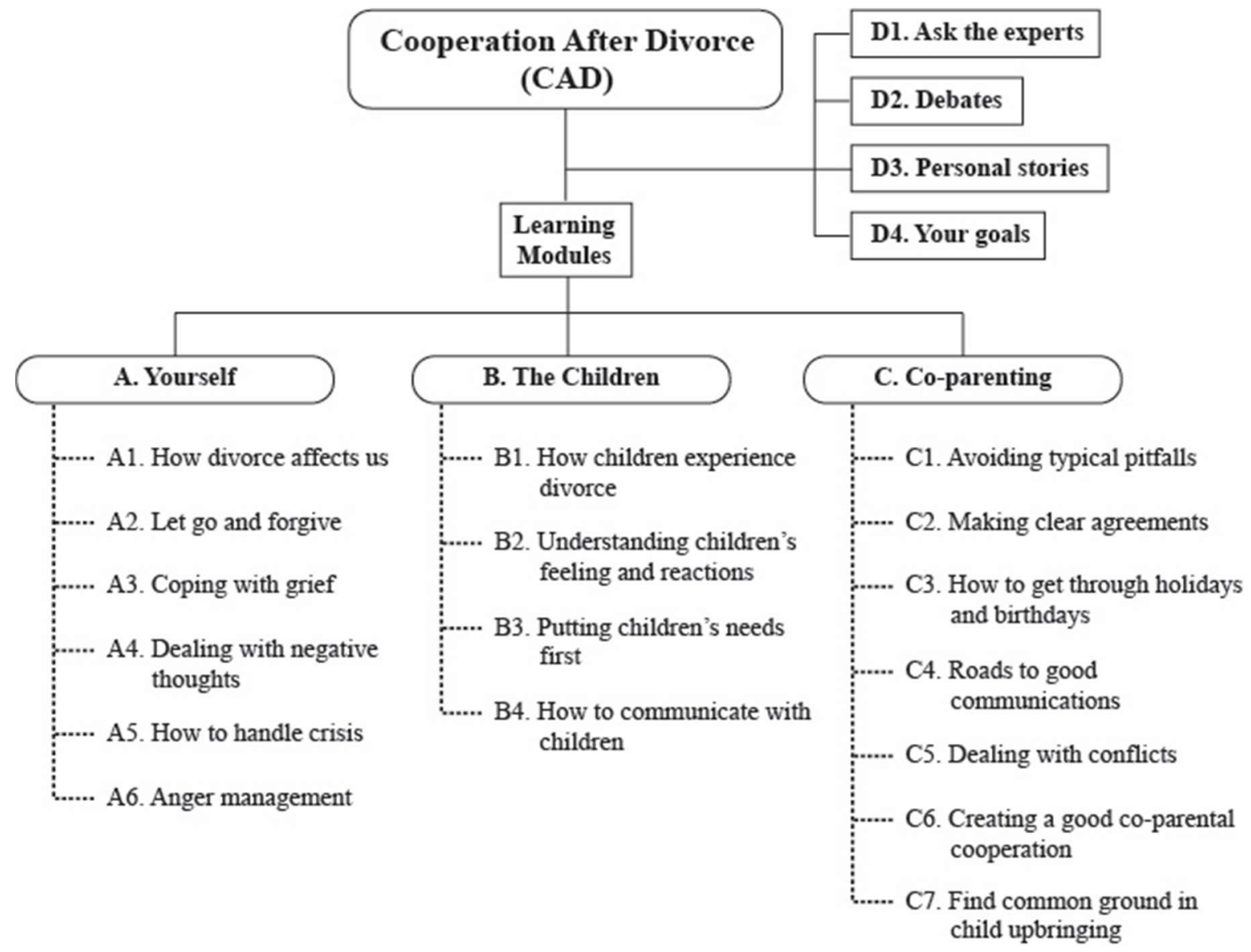




\begin{tabular}{|c|c|c|}
\hline ID & Title & Summary of content \\
\hline A1 & $\begin{array}{l}\text { How divorce } \\
\text { affects us }\end{array}$ & $\begin{array}{l}\text { - Divorce statistics \& research } \\
\text { - The most common reasons for divorce } \\
\text { - The consequences of divorce for both adults and children } \\
\text { - Where and how you can make a difference, prevent, or reduce negative } \\
\text { consequences }\end{array}$ \\
\hline A2 & $\begin{array}{l}\text { Let go and } \\
\text { forgive }\end{array}$ & $\begin{array}{l}\text { - } \text { Reasons why forgiveness can be helpful } \\
\text { - } \text { Definition of forgiveness } \\
\text { - } \text { How to forgive your ex } \\
\text { - How to forgive yourself }\end{array}$ \\
\hline A3 & Coping with grief & $\begin{array}{ll}\text { - } & \text { Definition of grief } \\
\text { - } & \text { How to embrace grief } \\
\text { - } & \text { How to tackle the new everyday life }\end{array}$ \\
\hline A4 & $\begin{array}{l}\text { Dealing with } \\
\text { negative thoughts }\end{array}$ & $\begin{array}{l}\text { - } \text { Reasons why negative thoughts appear } \\
\text { - How to frame negative streams of thoughts } \\
\text { - How to get a new perspective on your thoughts } \\
\text { - How to accept and embrace your thoughts }\end{array}$ \\
\hline A5 & $\begin{array}{l}\text { How to handle } \\
\text { crisis }\end{array}$ & $\begin{array}{l}\text { - Why many people experience a life crisis after divorce } \\
\text { - The most common feelings and reactions after divorce } \\
\text { - Psychological models that underlie these feeling and reactions } \\
\text { - How to get through the crisis }\end{array}$ \\
\hline A6 & $\begin{array}{l}\text { Anger } \\
\text { management }\end{array}$ & $\begin{array}{l}\text { - Understand the nature and function of anger } \\
\text { - How to discover your anger early } \\
\text { - Seven strategies to manage your anger }\end{array}$ \\
\hline B1 & $\begin{array}{l}\text { How children } \\
\text { experience } \\
\text { divorce }\end{array}$ & $\begin{array}{l}\text { - How children typically experience a divorce } \\
\text { - Learn how to see the divorce from your child's perspective }\end{array}$ \\
\hline B2 & $\begin{array}{l}\text { Understanding } \\
\text { children's } \\
\text { feelings and } \\
\text { reactions }\end{array}$ & $\begin{array}{l}\text { - Children's typical reactions to divorce } \\
\text { - The psychological reasons for your child's reactions } \\
\text { - Learn to perceive your child's reactions as invitations }\end{array}$ \\
\hline
\end{tabular}




\begin{tabular}{|c|c|c|}
\hline B3 & $\begin{array}{l}\text { Putting children's } \\
\text { needs first }\end{array}$ & $\begin{array}{l}\text { - Why children of divorce have special needs } \\
\text { - Learn what these special needs consist of } \\
\text { - How to distinguish your feelings from your child's needs } \\
\text { - How to accommodate your child's needs }\end{array}$ \\
\hline B4 & $\begin{array}{l}\text { How to } \\
\text { communicate } \\
\text { with children }\end{array}$ & $\begin{array}{l}\text { - Why children need to talk about the divorce } \\
\text { - How to get a good start, when you talk to your child } \\
\text { - How to communicate with children of different age ranges } \\
\text { - Useful communication techniques for all age ranges }\end{array}$ \\
\hline $\mathrm{C} 1$ & $\begin{array}{l}\text { Avoiding typical } \\
\text { pitfalls }\end{array}$ & $\begin{array}{l}\text { - What the ten worst pitfalls are } \\
\text { - How to avoid pitfalls } \\
\text { - Where you can learn more about these pitfalls }\end{array}$ \\
\hline $\mathrm{C} 2$ & $\begin{array}{l}\text { Making clear } \\
\text { agreements }\end{array}$ & $\begin{array}{l}\text { - How to arrange different agreements involving children } \\
\text { - What to be aware of when choosing your type of agreement } \\
\text { - } \quad \text { How to make clear agreements } \\
\text { - Where to find help making clear agreements }\end{array}$ \\
\hline C3 & $\begin{array}{l}\text { How to get } \\
\text { through holidays } \\
\text { and birthdays }\end{array}$ & $\begin{array}{l}\text { - The most important considerations regarding holidays and birthdays } \\
\text { - How to take the children's needs into your considerations }\end{array}$ \\
\hline $\mathrm{C} 4$ & $\begin{array}{l}\text { Roads to good } \\
\text { communications }\end{array}$ & $\begin{array}{l}\text { - Why communication is important } \\
\text { - What increases or impedes good communication } \\
\text { - How to communicate constructive in both digital and spoken communication }\end{array}$ \\
\hline C5 & $\begin{array}{l}\text { Dealing with } \\
\text { conflicts }\end{array}$ & $\begin{array}{l}\text { - The four most common reasons for conflict } \\
\text { - How to create a good process when you and your ex disagree } \\
\text { - Introduction to the conflict stairway } \\
\text { - How to find solutions and compromises }\end{array}$ \\
\hline C6 & $\begin{array}{l}\text { Creating a good } \\
\text { co-parental } \\
\text { cooperation }\end{array}$ & $\begin{array}{l}\text { - The five cooperation styles/metaphors } \\
\text { - Find out what kind of cooperation you have now } \\
\text { - What characterizes a cooperation that is "good enough" } \\
\text { - How to create a "new' relationship with your ex }\end{array}$ \\
\hline
\end{tabular}




\begin{tabular}{|l|l|ll|}
\hline C7 & $\begin{array}{l}\text { Find common } \\
\text { ground in child } \\
\text { rearing }\end{array}$ & $\begin{array}{l}\bullet \\
\bullet\end{array}$ & $\begin{array}{l}\text { The importance of having common framework and rules across two homes } \\
\text { How to find common ground }\end{array}$ \\
\hline D1 & Ask the experts & $\bullet$ & $\begin{array}{l}\text { Here you can ask the experts (psychologists and lawyers) about specific } \\
\text { situations or dilemmas. The experts will answer within 5 working days. }\end{array}$ \\
\hline D2 & Debate & $\begin{array}{l}\text { Here you can ask other users questions, share your experiences, and find } \\
\text { inspiration. }\end{array}$ \\
\hline D3 & Personal stories & $\begin{array}{l}\text { Four documentary videos with parents whom have been through a difficult } \\
\text { divorce but have managed to establish a working co-parenting cooperation } \\
\text { despite of the conflicts. }\end{array}$ \\
\hline D4 & Your goals & $\begin{array}{l}\text { Mark the goals that are most important to you and the platform will } \\
\text { recommend the most relevant modules to you. }\end{array}$ \\
\hline
\end{tabular}

The overall objective of the solution is to provide a combination of knowledge and tools, which increase the likelihood that divorce related knowledge and divorce relevant strategies pertaining to each of the modules are translated into actual behavior. Accordingly, all of the learning modules includes both psychoeducation, exercises, questions, and/or dilemmas. Three core communication and interaction principles are applied throughout the intervention: 1) A minimum of text is used in lieu of 'rich media' such as video, animation, illustrations, pictures, and voice-overs; 2) User activation such that users are activated every 2-5 minutes with exercises, questions, and/or dilemmas, where they reflect and work with their own situation; 3) The language and difficulty level challenge the users instead of aiming for the lowest common denominator. In CAD the aim is to provide the user with an experience, knowledge and skills they cannot get just by Googling. 


\section{Supplementary Materials 2.}

Logistic regression analyses of drop-out from baseline to 3-months. To determine if the attrition rate resulted in an attrition bias, multiple logistic regression analyses by group were performed to compare participants who completed only the baseline questionnaire to the rest of the sample. Predictors were sociodemographic variables (gender, age at survey, education, income), divorce-related characteristics (times divorced, marriage duration, number of children, conflict degree with a former spouse), and mental and physical health indicators (physical and mental health, stress, somatization, anxiety, and depression). 


\begin{tabular}{|c|c|c|c|c|}
\hline Variable & Estimate & Std. Error & OR & $p$ value \\
\hline Intervention (vs. Control) & 0.01 & 0.02 & 1.01 & 0.63 \\
\hline Women (vs. Men) & 0.02 & 0.03 & 1.02 & 0.50 \\
\hline Age & 0.00 & 0.00 & 1.00 & 0.02 \\
\hline Education_High & 1.00 & & 1.00 & \\
\hline Low & 0.02 & 0.03 & 1.02 & 0.47 \\
\hline _Medium & -0.03 & 0.03 & -0.97 & 0.37 \\
\hline Income_Above average & 1.00 & & 1.00 & \\
\hline _Below average & 0.00 & 0.04 & 1.00 & 0.96 \\
\hline _Average & 0.01 & 0.03 & 1.01 & 0.84 \\
\hline Number of Children & -0.01 & 0.01 & -0.99 & 0.43 \\
\hline Times Divorced_1 time & 1.00 & & 1.00 & \\
\hline 2 times & 0.00 & 0.04 & 1.00 & 0.95 \\
\hline _3 times & 0.07 & 0.10 & 1.07 & 0.49 \\
\hline _More than 3 times & 0.20 & 0.19 & 1.22 & 0.31 \\
\hline Marriage duration & 0.00 & 0.00 & 1.00 & 0.47 \\
\hline Conflict degree & 0.00 & 0.00 & 1.00 & 0.27 \\
\hline Mental Health Indicators & & & 1.00 & \\
\hline Physical Health & -0.05 & 0.02 & -0.95 & 0.01 \\
\hline Mental Health & 0.01 & 0.02 & 1.01 & 0.73 \\
\hline Stress & 0.00 & 0.00 & 1.00 & 0.65 \\
\hline Somatization & -0.01 & 0.03 & -1.00 & 0.85 \\
\hline Anxiety & 0.03 & 0.03 & 1.03 & 0.32 \\
\hline Depression & -0.01 & 0.03 & -0.90 & 0.58 \\
\hline
\end{tabular}

Note. $O R=$ Odds Ratio 